\title{
How banking sanctions influence on performance of foreign currency portfolio management
}

\author{
Mohammad Khodaei Valahzaghard $^{\mathrm{a}^{*}}$ and Mahmood Ansar
} \author{
C H R O N I C L E \\ Article history: \\ Received September 15, 2012 \\ Received in revised format \\ 20 December 2012 \\ Accepted 20 December 2012 \\ Available online \\ December 222012 \\ Keywords: \\ Portfolio optimization \\ Currency management \\ Exchange Portfolio Management
}

${ }^{a}$ Assist. Prof, Department of Financial Management, Science and Research branch, Islamic Azad university (IAU), Tehran, Iran ${ }^{b}$ M.A. Student, Department of Financial Management, Science and Research branch, Islamic Azad university (IAU), Tehran, Iran

\section{Introduction}

Currency market is one of the biggest markets and many believe that Forex is the biggest financial market in the world. Most banks in the world must deal with customers who hold different currencies and there must be a good currency management to manage the profitability. During the past few years, there has been a conflict on peaceful nuclear programs between the government of Iran and some western countries and we have seen several economic pressures on Iranian banking system. There is no doubt that any economic sanction could impact overall market in any country but the effects on foreign currency portfolio management needs to be investigated. During the past few years, several studies have been devoted on currency market in the world. According to Khodaei Valahzaghard et al. (2012), there have been tremendous fluctuations on different currencies, for instance, European common currency, Euro, has be fluctuated between 0.60 to 0.9 against US dollar.

*Corresponding author. Tel: +98-912-3443139

E-mail addresses: m_khodaei@iau-tnb.ac.ir (M. Khodaei Valahzaghard)

(C) 2013 Growing Science Ltd. All rights reserved.

doi: 10.5267/j.msl.2012.12.021 
These fluctuations can provide opportunities for management to earn some no-interest based profits by optimizing the foreign currency portfolios. Sanctions can effect these opportunities.

Daghighi Asl and Yarifard (2012) performed a study on relationship between no-interest based activities on performance of Iranian banks over the period of 2006-2011 using Pearson correlation as well as regression analysis. They implemented two independent variables where the first one was considered as a difference between other no-interest incomes with commission fee and the second one was the commission fee income. The result of their survey indicated that no-interest based activities had meaningful impacts on the performances of banks. In addition, there are some meaningful relationships among interest free activities, which were mostly in terms of negative relationships.

Khodaei Valahzaghard and Taherinejhad (2012) did a survey on selected Iranian banks operating actively over the period 2005- 2010. They studied the effects of four important variables including degree of financial leverage, bank size, working capital and liquidity on return on asset as a primary source of measuring profitability of Iranian banking system. They implemented Pearson correlation test along with simple and multi regression analysis to investigate the behavior of these four factors on profitability of banking system. Based on the survey, a high level of working capital and financial leverage resulted a lower profitability in Iranian privated banks.

In this paper, we investigate the effects of US sanctions on Iranian banking system in an empirical investigation one of the biggest Iranian banks.

\section{The proposed model}

The proposed model of this paper uses the idea originally developed by Fonseca et al. (2010) to find the optimum allocation of various currencies, we domesticated their model and develop KhodaeiAnsar Model (KA Model) to use it in this paper. The following notation summarizes details of our survey,

$n \quad$ Number of foreign currencies in portfolio,

$u_{i} \quad$ The amount of $i^{\text {th }}$ currency, which could be managed,

$x_{i j} \quad$ The percentage of $i^{\text {th }}$ currency converted to $j^{\text {th }}$ currency,

$c_{i j} \quad$ The exchange rate that convert $i^{\text {th }}$ currency to $j^{\text {th }}$ currency,

$a_{\$ j} \quad$ Exchange rate of $j^{\text {th }}$ currency to US dollar at the end of period,

$b_{\$} \quad$ Central bank base rate of US dollar at the end of period,

$x_{i i} \quad$ The amount of $i^{\text {th }}$ currency, which is not converted to another currency,

$b_{i} \quad$ Central bank base rate of currency $i$ at the end of period,

$u_{j} \quad$ Amount of other currencies excluding $i^{t h}$ currency, which could be managed,

$x_{j i} \quad$ Amount of other currencies excluding $i^{\text {th }}$ currency, which are exchanged to $i^{\text {th }}$ currency,

$b_{j} \quad$ Central bank base rate of $j^{\text {th }}$ currency at the end of period,

cb Base capital of the bank at the end of period determined by central bank,

$b_{i}^{-} \quad$ Central bank base rate of the $i^{\text {th }}$ currency at the beginning of period $i$,

$c b^{-} \quad$ Base capital of the bank at the beginning of period determined by central bank,

$o_{i} \quad$ Permitted open position on $i^{\text {th }}$ currency determined by central bank,

$e_{i} \quad$ The maximum deviation on permitted open position on $i^{\text {th }}$ currency determined by experts, 
$o_{t} \quad$ Total permitted open position on foreign currency portfolio determined by central bank,

$e_{t} \quad$ The maximum deviation on total permitted open position on foreign currency portfolio determined by experts.

Khodaei-Ansar Model (KA Model) is the proposed model of this paper and formulated as follows,

$\frac{\max }{\min } \sum_{i=1}^{n} \sum_{j=1}^{n}\left(u_{i} x_{i j} c_{i j} a_{\$ j} b_{\$}\right)$

subject to

$$
\begin{aligned}
& \frac{\left[\left(u_{i} x_{i i} b_{i}\right)+\sum\left(u_{j} x_{j i} b_{j}\right)\right]}{c b} \leq \max \left[\left(\left|\frac{u_{i} b_{i}^{-}}{c b^{-}}\right|+e_{i}\right),\left(o_{i}+e_{i}\right)\right] \\
& \frac{\left[\left(u_{i} x_{i i} b_{i}\right)+\sum\left(u_{j} x_{j i} b_{j}\right)\right]}{c b} \geq-\max \left[\left(\left|\frac{u_{i} b_{i}^{-}}{c b^{-}}\right|+e_{i}\right),\left(o_{i}+e_{i}\right)\right] \\
& \frac{\sum\left(u_{i} x_{i j} b_{i}\right)}{c b} \leq \max \left[\left(\left|\frac{\sum\left(u_{i} b_{i}^{-}\right)}{c b^{-}}\right|+e_{t}\right),\left(o_{t}+e_{t}\right)\right] \\
& \frac{\sum\left(u_{i} x_{i j} b_{i}\right)}{c b} \geq-\max \left[\left(\left|\frac{\sum\left(u_{i} b_{i}^{-}\right)}{c b^{-}}\right|+e_{t}\right),\left(o_{t}+e_{t}\right)\right] \\
& \sum x_{i j}=1
\end{aligned}
$$

Eq. (1) is the objective function of the proposed model, which optimizes the gain from changes in different currencies. Eq. (2) to Eq. (5) determine the maximum changes in asset allocation from different currencies and finally Eq. (6) is the budget constraint. The results of portfolio optimization determines lost profit and unrealized loss and using the idea of Technique for Order of Preference by Similarity to Ideal Solution (TOPSIS) (Yoon \& Hwang, 1995) we rank the resulted data as follows,

foreign currency portfolio management performance $=\frac{\text { unrealized loss }}{\text { unrealized loss }+ \text { lost profit }}$

TOPSIS, developed by Hwang and Yoon in 1981, is an straightforward but sophisticated ranking technique implemented in many real-world applications of science and engineering (Chang et al., 2010). The standard TOPSIS method selects various alternatives, which have the shortest distance from the positive ideal solutions and the longest distance from the negative-ideal solutions. The positive ideal solution maximizes the suitable criteria and minimizes the undesirable criteria, whereas the negative ideal solution maximizes the undesirable criteria and minimizes the desirable criteria (Chen \& Hwang, 1992; Yoon \& Hwang, 1995).

There are literally various applications of TOPSIS used in different areas of scientific societies and there are different extensions of TOPSIS such as fuzzy TOPSIS. Amiri (2010) studied project selection for oil-fields development by implementing the AHP and fuzzy TOPSIS techniques.

The proposed model of this paper considers the weekly information two years before and after sanctions occurred in Iranian banking system. Therefore, the study uses 210 weekly data and proposes a method to analyze the data to measure the performance of bank's foreign currency 
portfolio management before and after sanction happens. We solve the proposed model 420 times to generate two pairs of data and using Eq. (7) we may be able to calculate foreign currency portfolio management performance. The main question of this survey considers whether there is a difference between the foreign currency portfolio management performance before and after sanctions happen.

\section{The results}

We first present details of our 105 statistical observations before sanctions happen including mean, standard deviation as well as Kolmogorev-smirnov test (KS) (Boes et al., 1974) to find out whether data are normally distributed or not. Table 1 shows the results.

Table 1

Basic statistics for 105 observations before sanction period

\begin{tabular}{|c|c|c|c|c|c|c|c|c|c|}
\hline Currency & Mean & Median & $\min$ & $\max$ & Std. dev. & Variance & Skewness & Kurtosis & Normality test \\
\hline base rate of US dollar & 9,291 & 9,256 & 8,957 & 9,906 & 167 & 27,732 & 6.4 & 8 & Rejected \\
\hline base rate of Euro & 13,188 & 13,239 & 11,722 & 14,535 & 867 & 751,570 & -0.10 & -3 & Confirmed \\
\hline base rate of Won & 10 & 10 & 0 & 11 & 1 & 2 & -22.6 & 70 & Rejected \\
\hline base rate of Turkish Lire & 0 & 0 & 0 & 0 & 0 & 0 & -4.3 & -4 & Rejected \\
\hline base rate of Japanese Yen & 83 & 81 & 75 & 100 & 6 & 31 & 3.0 & 0.5 & Confirmed \\
\hline base rate of UAE Dirham & 2,530 & 2,522 & 2,439 & 2,697 & 45 & 2,044 & 6.3 & 8 & Rejected \\
\hline Net foreign assets (billion Rials) & $-9,122$ & $-8,820$ & $-20,501$ & 965 & 5,419 & $29,361,946$ & -1.1 & -2 & Rejected \\
\hline Manageable US dollar (million) & 146 & 83 & 11 & 1,008 & 196 & 38,430 & 13.8 & 22 & Rejected \\
\hline Manageable Euro (million) & 304 & 273 & 74 & 796 & 149 & 22,089 & 3.4 & 1 & Rejected \\
\hline Manageable Won (million) & 141 & 129 & 0 & 430 & 151 & 22,788 & 2.3 & -2 & Rejected \\
\hline Manageable Turkish Lire (million) & 0 & 0 & 0 & 0 & 0 & 0 & --- & --- & Rejected \\
\hline Manageable Japanese Yen (million) & 3,443 & 3,492 & 878 & 8,266 & 1,537 & $2,362,901$ & 2.3 & 1 & Confirmed \\
\hline Manageable UAE Dirham (million) & 334 & 373 & 25 & 868 & 205 & 41,845 & 0.3 & -2 & Confirmed \\
\hline lost profit (thousand US dollar) & 3,175 & 2,117 & 130 & 25,408 & 3,715 & $13,802,006$ & 15.9 & 37 & Rejected \\
\hline unrealized loss (thousand US dollar) & 6,315 & 4,902 & 687 & 47,089 & 6,860 & $47,065,865$ & 24.3 & -64 & Rejected \\
\hline Rank of portfolio management (\%) & $64.0 \%$ & $65.2 \%$ & $9.1 \%$ & $97.9 \%$ & $21.7 \%$ & $4.7 \%$ & -1.7 & -3 & Confirmed \\
\hline
\end{tabular}

As we can observe from the results of Table 1, most data are not normally distributed. We have also performed similar investigation after sanction happened. Table 2 demonstrates details of our results.

Table 2

Basic statistics for 105 observations after sanction period

\begin{tabular}{|c|c|c|c|c|c|c|c|c|c|}
\hline Currency & Mean & Median & $\min$ & $\max$ & Std. dev. & Variance & Skewness & Kurtosis & Normality test \\
\hline base rate of US dollar & 10,036 & 9,979 & 9,560 & 10,537 & 239 & 57,041 & 2.1 & -1 & Rejected \\
\hline base rate of Euro & 13,610 & 13,574 & 12,177 & 14,946 & 689 & 475,011 & 0.3 & -2 & Confirmed \\
\hline base rate of Won & 8 & 8 & 6 & 9 & 1 & 0 & -2.9 & -1 & Rejected \\
\hline base rate of Turkish Lire & 7,374 & 7,431 & 0 & 11,394 & 4,084 & $16,677,834$ & -3.9 & -1 & Rejected \\
\hline base rate of Japanese Yen & 110 & 109 & 99 & 128 & 7 & 50 & 3.5 & 0 & Rejected \\
\hline base rate of UAE Dirham & 2,733 & 2,717 & 2,603 & 2,869 & 65 & 4,240 & 2.1 & -1 & Rejected \\
\hline Net foreign assets (billion Rials) & 1,130 & 3,261 & -16848 & 7,433 & 5,148 & $26,501,830$ & -7.7 & 6 & Rejected \\
\hline Manageable US dollar (million) & 586 & 425 & 88 & 1,720 & 422 & 178,118 & 2.9 & -1 & Rejected \\
\hline Manageable Euro (million) & 1,325 & 1,192 & 625 & 2,811 & 562 & 316,254 & 2.6 & -1 & Rejected \\
\hline Manageable won (million) & 299 & 246 & 0 & 888 & 235 & 55,262 & 2.4 & -1 & Rejected \\
\hline Manageable Turkish Lire (million) & 2 & 0 & 0 & 50 & 8 & 67 & 21.2 & 53 & Rejected \\
\hline Manageable Japanese Yen (million) & 2,152 & 1,885 & 380 & 6,672 & 1,469 & $2,158,113$ & 4.7 & 2 & Rejected \\
\hline Manageable UAE Dirham (million) & 873 & 897 & 265 & 1,633 & 324 & 104,864 & -0.3 & -2 & Confirmed \\
\hline lost profit (thousand US dollar) & 6,449 & 4,976 & 448 & 32,164 & 5,295 & $28,038,212$ & 8.8 & 13 & Rejected \\
\hline unrealized loss (thousand US dollar) & 6,318 & 4,799 & 550 & 25,821 & $-4,829$ & $-23,315,954$ & 6.5 & -6 & Rejected \\
\hline Rank of portfolio management (\%) & $49.5 \%$ & $48.8 \%$ & $9.7 \%$ & $93.6 \%$ & $25.2 \%$ & $6.4 \%$ & 0.5 & -3 & Confirmed \\
\hline
\end{tabular}

We now investigate whether two sets of data are normally distributed using Kolmogorev-smirnov test (KS). Note that the sanction against Iranian banking system was posed on October, 25, 2008. Table 3 demonstrates summarizes details of our findings.

Table 3

The results of Kolmogorev-smirnov test (KS) before/after the sanction posed on Iranian banks

\begin{tabular}{lcccc}
\hline Period & Number of observations & $\mathrm{Z}$ & Sig. & Results \\
\hline Before sanction & 105 & 0.955 & 0.322 & Data are normally distributed \\
After sanction & 105 & 1.218 & 0.103 & Data are normally distributed \\
Before/After sanction & 210 & 1.109 & 0.171 & Data are normally distributed \\
\hline
\end{tabular}


We also need to make sure two sets of data maintain the same variances and this is accomplished using Homogeneity of Variances based on Levene Statistic (Levene, 1960). Table 4 summarizes the results of our tests between the ranking of two sets of data.

\section{Table 4}

The results of comparing mean and variances of two sets of data using parametric test

\begin{tabular}{llllrlll}
\hline & & & & \multicolumn{2}{c}{ Leven } & \multicolumn{2}{c}{ t-test } \\
\cline { 5 - 8 } Period & $\mathrm{N}$ & Mean rank & Std. Dev. & Hypothesis & Sig. & Hypothesis & Sig. \\
\hline Before & 105 & $64.0 \%$ & $21.7 \%$ & $H_{0}: \sigma_{1}^{2}=\sigma_{2}^{2}$ & 0.020 & $H_{0}: \mu_{1}=\mu_{2}$ & 0.000 \\
After & 105 & $49.7 \%$ & $24.6 \%$ & $H_{1}: \sigma_{1}^{2} \neq \sigma_{2}^{2}$ & & $H_{1}: \mu_{1} \neq \mu_{2}$ & \\
\hline
\end{tabular}

As we can observe from the results of Table 4, both null hypotheses are rejected when the level of significance is five percent. In other words, two sets of data have different mean and variances. In order to validate the results of Table 4, we have decided to use non-parametric tests to examine the results using $\mathrm{U}$ - Mann-Whitney test and Table 5 shows the results.

\section{Table 5}

The results of comparing mean and variances of two sets of data using U - Mann-Whitney

\begin{tabular}{llcccc}
\hline Period & $\mathrm{N}$ & Mean rank & Hypothesis & $\mathrm{Z}$ & Sig. \\
\hline Before & 105 & 123.27 & $H_{0}: \sigma_{1}^{2}=\sigma_{2}^{2}$ & -4.239 & 0.000 \\
After & 105 & 87.73 & $H_{1}: \sigma_{1}^{2} \neq \sigma_{2}^{2}$ & & \\
\hline
\end{tabular}

The result of Table 5 rejects the null hypothesis and we can conclude that there are, indeed, some differences between the mean rank of foreign currency portfolio management performance, which confirms our findings based on parametric survey.

\section{Conclusion}

In this paper, we have analyzed the impact of sanction posed on performance of foreign currency portfolio management in Iranian banks. The proposed model of this paper has gathered the necessary data for two years before and after the sanction, which was originally started on 25, October, 2008. The survey was performed over the period 2006-2010. The proposed study of this paper developed a mathematical model to find the optimal allocation of currency allocation from profitability view and the results are ranked based on an idea similar to what we have seen in TOPSIS technique. Finally, we have compared the means of two set of data based on parametric and non-parametric analysis. The results of both statistical tests have revealed that sanction has influenced the performance of foreign currency portfolio management, significantly.

\section{Acknowledgment}

The authors would like to thank the officials of Centeral Bank for providing the necessary data required for the accomplishment of this survey.

\section{References}

Amiri, M. P. (2010). Project selection for oil-fields development by using the AHP and fuzzy TOPSIS methods. Expert Systems with Applications, 37, 6218-6224. 
Boes, D. C., Graybill, F. A., \& Mood, A. M. (1974). Introduction to the Theory of Statistics. $3^{\text {rd }}$ ed. New York: McGraw-Hill, 1974.

Chen, S. J., \& Hwang, C. L. (1992). Fuzzy multiple attribute decision making: Methods and applications. Berlin: Springer-Verlag.

Chang, C. H., Lin, J. J., Lin, J. H., \& Chiang, M. C. (2010). Domestic open-end equity mutual fund performance evaluation using extended TOPSIS method with different distance approaches. Expert Systems with Applications, 37, 4642-4649.

Daghighi Asl, A., \& Yarifard, S. (2012). A study on relationship between no-interest based activities on performance of Iranian banks. Management Science Letters, 2(7), 2601-2606.

Fonseca, R.J., Wiesemann, W., \& Rustem, B. (2010). Robust international portfolio management. Working Papers 029, COMISEF.

Khodaei Valahzaghard, M., Taherinejhad, A. (2012). The impact of working capital and financial structure on profitability of islamic banking industry. Management Science Letters, 2(7), 26252630.

Levene, H. (1960). Robust tests for equality of variances. In Ingram Olkin, Harold Hotelling. Stanford University Press. pp. 278-292.

Hwang, C. L., \& Yoon, k. (1981). Multiple attribute decision making: Methods and applications: a state-of-the-art survey. Springer-Verlag.

Yoon, K. P., \& Hwang, C. L. (1995). Multiple attribute decision making. Thousand Oaks, CA: Sage Publication. 